\title{
Europium Incorporated into Titanium Oxide by the Sol-Gel Method
}

\author{
Lucas Alonso Rocha, Lilian Rodrigues Avila, Bruno Leonardo Caetano, Eduardo Ferreira Molina, \\ Hérica Cristina Sacco, Katia Jorge Ciuffi, Paulo Sergio Calefi, Eduardo José Nassar* \\ Universidade de Franca, Av. Dr. Armando Salles de Oliveira, 201, C.P. 82, \\ 14404-600 Franca - SP, Brazil
}

Received: March 3, 2005; Revised: June 28, 2005

\begin{abstract}
In this work titanium sol was prepared from tetraethylorthotitanate (TEOT) in ethanol, stabilized with betadiketonate 2,4 pentanedione in molar ratio 1:1 homogenized by magnetic stirring, europium ion was add as structural probe. The xerogels were heat treated at 500,750 and $1000{ }^{\circ} \mathrm{C}$ and the characterization was realized by $\mathrm{x}$-ray diffraction (XRD), transmission electron microscopy (TEM), thermogravimetric analysis (TGA/DSC) and photoluminescence (PL). The excitation spectra of Eu (III) ion present maximum in $394 \mathrm{~nm}$ correspondent to ${ }^{5} \mathrm{~L}_{6}$ level and emission spectra present bands characteristic transitions arising from the ${ }^{5} \mathrm{D}_{0} \rightarrow{ }^{7} \mathrm{~F}_{\mathrm{J}}(\mathrm{J}=0,1,2$, 3, 4) manifolds to samples treat at 500 and $750{ }^{\circ} \mathrm{C}$. The Eu (III) emission disappear, when heated at $1000{ }^{\circ} \mathrm{C}$, probably due to phase transition anatase to rutile and migrations of ions to the external surface that was proved by x-ray diffraction, transmission electronic microscopy and the thermogravimetric analyses of xerogels.
\end{abstract}

Keywords: europium (III), xerogels, luminescence, TEM

\section{Introduction}

Titanium oxide has been investigated widely in the form of bulk, powders, films and membranes ${ }^{1-3}$ and can be applied in several fields such as electronics, gas and humidity sensors, photocatalytic properties and others. Nanocrystalline titania was synthesized chemically by the sol-gel route. Titania undergoes a transformation phase from the low-temperature anatase phase to rutile above $450{ }^{\circ} \mathrm{C}$, and has been found to extend up to $1000{ }^{\circ} \mathrm{C}$, depending on the method of preparation and on the presence of suitable dopant oxides ${ }^{1}$.

The advantages of sol-gel powders over conventional powders is that their size and shape, molecular scale homogeneity, and enhanced reactivity (lower processing temperatures) ${ }^{4}$ can be controlled.

Excitation of the lanthanide in such schemes occurs with the absorption of light by a coordinating ligand and the subsequent transfer of its electronic energy to the emissive excited state manifold of the lanthanide ion ${ }^{5}$. The electronic energy states of lanthanide $4 f^{n}$ configurations are only minimally affected by their surroundings owing to the effective shielding of the $4 f$ electrons from the external field by the $5 s^{2} 5 p^{6}$ arrangement. Therefore, these energy states remain practically invariable for a given ion in all its compounds and in different environments. These absorption and emission spectra of lanthanide (III) ions give sharp, spectrally narrow bands ${ }^{6}$.

From the technological viewpoint, a prospective way to synthesize luminescent materials is by the sol-gel method, whose main advantages are its low cost, simplicity, flexibility and absence of induced radiation defects ${ }^{7-9}$.

In this work, we studied the synthesis and characterization of xerogels (powder) of titanium doped with europium III and prepared by the conventional sol-gel process. After heat treatment at various temperatures, the samples were studied by transmission electron microscopy (TEM), thermogravimetric analysis (TGA/DTA/DSC), photoluminescence (PL) and x-ray diffraction.

\section{Experimental Section}

Titanium sol was prepared from tetraethylorthotitanate (TEOT from Aldrich) in ethanol (EtOH), and the metal alkoxide reaction was controlled by beta-diketone 2,4 pentanedione (acac) in a molar ratio of 1:1. $1.0 \mathrm{mmol}$ of acac was added to $10 \mathrm{~mL}$ of EtOH under magnetic stirring. After 5 minutes the $1.0 \mathrm{mmol}$ of TEOT was added to the mixture. The ethanolic europium chloride solution $\left(\mathrm{EuCl}_{3}\right)$ was added to the sol on molar percentages of $0.1,0.2$ and $0.3 \%$ and the sol was homogenized by magnetic stirring for 30 minutes.

These solutions were dried at room temperature and the resulting xerogels (powders) were heat-treated at 500, 750 and $1000{ }^{\circ} \mathrm{C}$ in porcelain crucibles.

Luminescence data were obtained under both continuous (450W) and pulsed ( $5 \mathrm{~J} /$ pulse, $3 \mu$ s bandwidth) Xe lamp excitation with a SPEX FLUOROLOG F2121 spectrofluorimeter at room temperature. All the spectra were corrected by spectrometer optics, lamp output and detector response.

X-ray diffractograms (XRD) were obtained using a Siemens (D 5005) X-ray diffractometer and $\mathrm{Cu} \mathrm{K}_{\alpha}$ radiation.

A thermogravimetric analysis (TGA/DTA/DSC) was carried out (Instruments SDT Q600 - Simultaneous DSC-DTA-TGA) in air at a heating rate of $20{ }^{\circ} \mathrm{C} \mathrm{min}-1$, from 25 to $1500{ }^{\circ} \mathrm{C}$.

The morphology of the systems was investigated by transmission electron microscopy (TEM) of a drop of power suspension deposited on a copper grid. The TEM analysis was performed with a $200 \mathrm{kV}$ Philips CM 200 microscope.

\section{Results and Discussion}

The synthesis of $\mathrm{TiO}_{2}$ networks by the sol-gel process consists of forming an inorganic network through the hydrolysis and polymerization of the required titanium alkoxide in ethanolic solution, followed by gelation to form titanium xerogel doped Eu (III) ions.

Figure 1 depicts the excitation and emission spectra of a sample doped with a molar percentage of $0.3 \%$ of europium.

The photoluminescence data of Eu (III) ions displayed a similar behavior. In the excitation spectra of the samples heated at 500 and $700{ }^{\circ} \mathrm{C}$, the maximum, which appeared at $394 \mathrm{~nm}$, was ascribed to the ${ }^{5} \mathrm{~L}_{6}$ level of Eu (III). However, this band was not observed in the 
sample heated at $1000{ }^{\circ} \mathrm{C}$. The emission spectra presented transitions arising from ${ }^{5} \mathrm{D}_{0}$ to ${ }^{7} \mathrm{~F}_{\mathrm{j}}(\mathrm{J}=0,1,2,3$ and 4) manifolds excited at their maximum ${ }^{10}$ in the samples heated at 500 and $700{ }^{\circ} \mathrm{C}$, but the sample heated at $1000{ }^{\circ} \mathrm{C}$ showed no $\mathrm{Eu}$ (III) luminescence.

The decay curve for the ${ }^{5} \mathrm{D}_{0} \rightarrow{ }^{7} \mathrm{~F}_{2}$ transition of $\mathrm{Eu}$ (III) in the $\mathrm{TiO}_{2}$ matrix consists of a monoexponential function, resulting in a lifetime (ms) of about $0.45 \pm 0.01$ for the samples heated at $500{ }^{\circ} \mathrm{C}$ and of $0.40 \pm 0.03$ for those heated at $750{ }^{\circ} \mathrm{C}$. This result indicates that $\mathrm{Eu}$ (III) occupies only one type of site in these materials. The lifetime was not obtained for the samples heated at $1000{ }^{\circ} \mathrm{C}$.

The excitation energy of Eu (III) can be absorbed by the vibration of ligands, thus decreasing the lifetime ${ }^{11}$. Because of the electric-dipole character of Eu (III), the intensities of the ${ }^{5} \mathrm{D}_{0} \rightarrow{ }^{7} \mathrm{~F}_{0}$ and ${ }^{5} \mathrm{D}_{0} \rightarrow$ ${ }^{7} \mathrm{~F}_{2}$ transitions are strongly dependent on the surrounding $\mathrm{Eu}$ (III). The corresponding band of ${ }^{5} \mathrm{D}_{0} \rightarrow{ }^{7} \mathrm{~F}_{1}$ transition has a magnetic dipole nature and its intensity is not affected by its surroundings ${ }^{12}$. In both emission spectra, the bands corresponding to the ${ }^{5} \mathrm{D}_{0} \rightarrow{ }^{7} \mathrm{~F}_{2}$ transitions showed a higher intensity than the ${ }^{5} \mathrm{D}_{0} \rightarrow{ }^{7} \mathrm{~F}_{1}$ transitions. This difference indicated that the Eu (III) occupies sites without an inversion center ${ }^{13-15}$. The presence of ${ }^{5} \mathrm{D}_{0} \rightarrow{ }^{7} \mathrm{~F}_{0}$ transitions indicates that the Eu (III) is located in a site with a $\mathrm{C}_{\mathrm{nv}}, \mathrm{C}_{\mathrm{n}}$ or $\mathrm{C}_{\mathrm{s}}$ symmetry ${ }^{16}$. The presence of nonhomogeneous sites in the $\mathrm{TiO}_{2}$ structure was observed based on the band-width emission ${ }^{17}$.

The luminescence of $\mathrm{Eu}$ (III) ions doped in xerogels and heat-treated at different temperatures $\left(500,750{ }^{\circ} \mathrm{C}\right)$ shows similar luminescence bands. However, from $1000{ }^{\circ} \mathrm{C}$ up, the emission of $\mathrm{Eu}$ (III) ions disappeared, probably due to a phase transition from anatase to rutile and to migrations of ions to the external surface, as confirmed, respectively, by x-ray diffraction and transmission electronic microscopy. A large quantity of Eu (III) appeared on the surface of titanium oxide heated at $1000{ }^{\circ} \mathrm{C}$, as observed by Energy Dispersive x-ray Analysis (EDX), and quenching occured due to the high concentration of Eu (III). The transfer of emissive center energy to the level of another centre promoted a loss of energy.

$\mathrm{X}$-ray powder diffraction measurements indicated that the differences between percentages of europium were insignificant. Figure 2 illustrates the x-ray diffraction patterns, showing that the material was totally amorphous at room temperature. Crystallization started at $500{ }^{\circ} \mathrm{C}$ and, at $750{ }^{\circ} \mathrm{C}$, the sample's appearance was almost totally crystalline. After further increasing the treatment temperature to $1000^{\circ} \mathrm{C}$, the material presented a totally crystalline structure ${ }^{1}$.

The x-ray diffraction measurements showed that the material was completely amorphous at room temperature and that the onset of crystallization in the anatase phase occurred at $500{ }^{\circ} \mathrm{C}$, while sample's appearance was almost totally crystalline in the same phase at $750{ }^{\circ} \mathrm{C}^{18}$. After increasing the treatment temperature to $1000{ }^{\circ} \mathrm{C}$, the material showed a totally crystalline structure in the rutile phase.

The xerogels' thermal stability was investigated by thermogravimetric analysis of all the samples. However, Figure 3 shows only the xerogel at $0.3 \%$, since the results of the materials containing different percentages of europium were similar.

The TGA/DTA/DSC presented a mass loss between 50 and $250{ }^{\circ} \mathrm{C}$, and another between 350 and $450{ }^{\circ} \mathrm{C}$. A structural change occurred from 450 to $750{ }^{\circ} \mathrm{C}$ and from 950 to $1100{ }^{\circ} \mathrm{C}$, with DTA revealing two exothermic peaks at $450-750{ }^{\circ} \mathrm{C}$ and an endothermic peak at $1000^{\circ} \mathrm{C}$.

The thermal stability of the xerogels was investigated by TGA/ DTA/DSC. The DTA curves of the materials displayed up to two exothermic peaks, one at 300 and another at $450{ }^{\circ} \mathrm{C}$. Weight loss was observed in the same region due to pyrolysis of the organic group, dehydroxylation and collapse of the layered structure, and recrystallization of the pyrolysis product into oxides ${ }^{19}$.

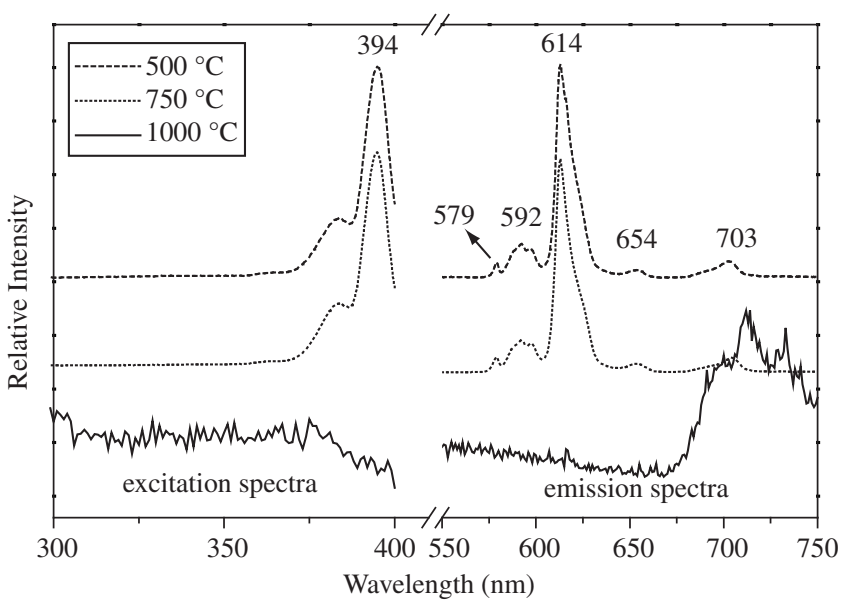

Figure 1. Excitation (left) and emission (right) spectra of Eu III ions (0.3\%) entrapped in xerogel heat treated at different temperatures.

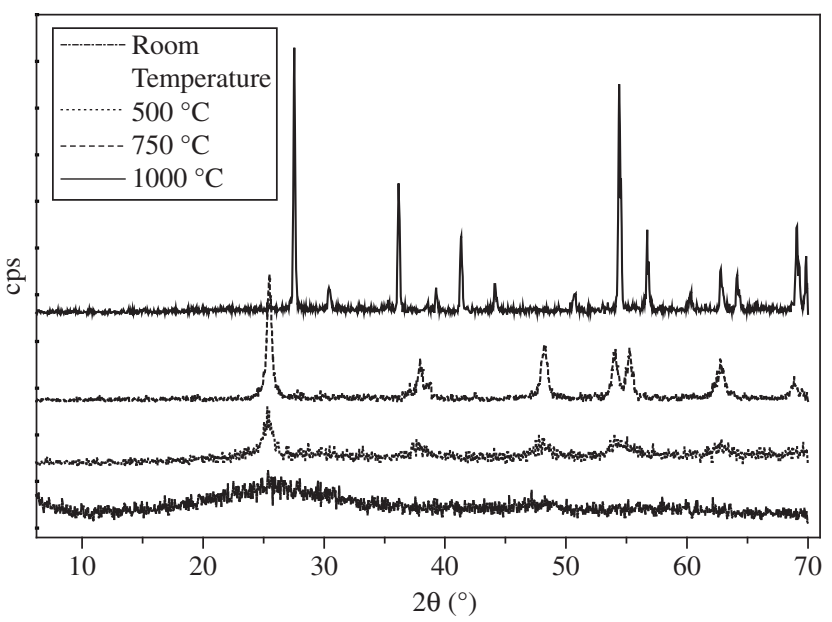

Figure 2. X-ray diffraction of xerogels doped with $0.3 \%$ mol of europium and heat-treated at different temperatures.

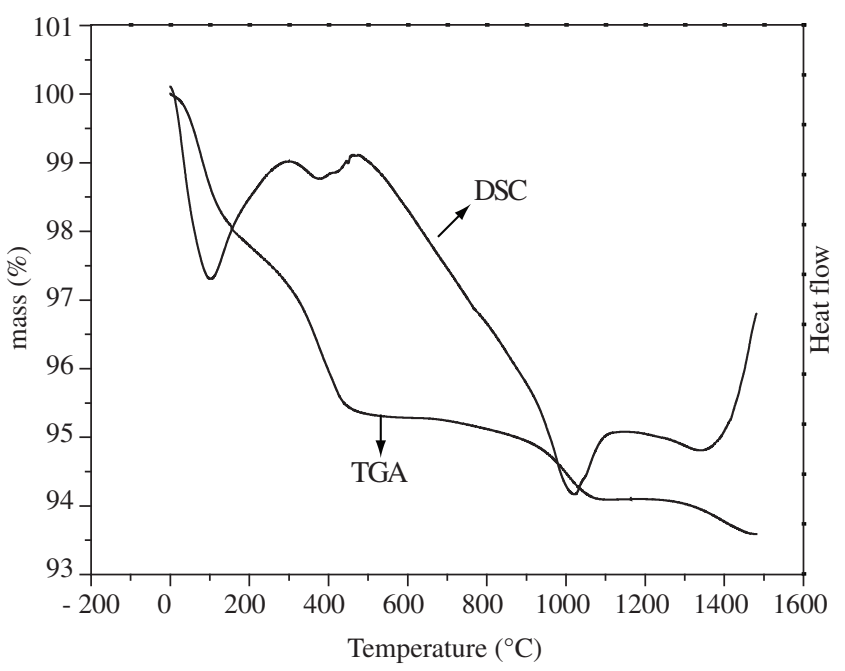

Figure 3. Thermogravimetric analysis (TGA/DTA/DSC) of xerogel at $0.3 \%$. 
The TGA in Figure 3 indicates that the first mass loss corresponded to a loss of water and solvent molecules which were only adsorbed in material $\left(50-250^{\circ} \mathrm{C}\right)$ while the second mass loss was related to the loss of organic groups attached to the material $\left(300-450{ }^{\circ} \mathrm{C}\right)$. Another weight loss occurred between $950-1050{ }^{\circ} \mathrm{C}$, corresponding to loss of oxygen molecules due to structural changes.

The TGA showed a gradual mass loss from 450 to $750{ }^{\circ} \mathrm{C}$, relating to the structural transition from amorphous to anatase, which was confirmed by DSC. An endothermic peak relating to the transition of anatase to rutile phase appeared at $1000{ }^{\circ} \mathrm{C}$.

Figure 4 shows a TEM image of $\mathrm{TiO}_{2}: \mathrm{Eu}$ (III) heat-treated at different temperatures. Figure $4 \mathrm{c}$ depicts a sample heat-treated up to $1000{ }^{\circ} \mathrm{C}$, showing migrations of Eu (III) ions to the material's external surface.

Figure 4a contains a TEM image of xerogels treated at $500{ }^{\circ} \mathrm{C}$. The agglomerate displayed a diameter not larger than $50 \mathrm{~nm}$, with crystallization beginning in the anatase phase, and the EDX measurements were congruent with $\mathrm{TiO}_{2}$ containing a low percentage of europium, probably due to the symmetry. In Figure 4b, the material treated at $750{ }^{\circ} \mathrm{C}$ showed a diameter of about $35 \mathrm{~nm}$ and was almost entirely crystalline in the anatase phase. The xerogel presented a mixture similar to that of the sample treated at $500{ }^{\circ} \mathrm{C}$. Figure $4 \mathrm{c}$ shows a TEM image of material treated at $1000{ }^{\circ} \mathrm{C}$, presenting a completely crystalline structure in rutile phase, which was confirmed by x-ray powder diffraction and the selected area diffraction pattern (SADP). The EDX measurements revealed the consistence of titanium oxide with a high percentage of europium. In the rutile phase, $\mathrm{Eu}$ (III) ions migrated to the external surface of the material, forming what looks like europium or metallic oxide, which appears as white dots in Figure 4c. This formation was responsible for quenching the luminescence of the Eu (III) ions and was probably caused by the transition from anatase to rutile phase, as confirmed by DSC and $\mathrm{x}$-ray powder diffraction.

\section{Conclusions}

The luminescence of Eu (III) ions in titanium oxide depends on the surroundings and the material presents a new structure, the rutile phase, when the temperature reaches $1000{ }^{\circ} \mathrm{C}$. In this phase, Eu (III) ions cannot occupy an intermediary position in the unit cell, giving rise to migrations to the material's external surface and extinguishing the luminescence.

Our x-ray and thermal analyses confirmed the phase change and the TEM analysis confirmed the migrations of Eu (III) ions to the surface.

We conclude that the preparation of titanium oxide by the sol-gel method is more cost-effective than other process, and that the short time and rapid definition of temperature-dependent phases is very important in these materials' applications.

\section{Acknowledgments}

The authors are grateful to FAPESP and CAPES (Brazil) for the financial support of this work.

\section{References}

1. Sibu CP, Kumar SR, Mukundan P, Warrier KGK. Structural Modifications and Associated Properties of Lanthanum Oxide Doped Sol-Gel Nanosized Titanium Oxide. Chemistry Materials. 2002; 14(7):2876-2881.

2. Pabón E, Retuert J, Quijada R, Zarate $\mathrm{A}$. $\mathrm{TiO}_{2}-\mathrm{SiO}_{2}$ mixed oxides prepared by a combined sol-gel and polymer inclusion method. Microporous and Mesoporous Materials. 2004; 67(2-3):195-203.

3. OoKa C, Yoshida H, Suzuki K, Hattori T. Highly hydrophobic $\mathrm{TiO}_{2}$ pillared clay for photocatalytic degradation of organic compounds in water. Microporous and Mesoporous Materials. 2004; 67(2-3):143-150.

4. Brinker CJ, Scherer GW. Sol-Gel Science: the Physics and Chemistry of Sol-Gel Processing. Academic Press, San Diego, 1990; p. 858.

5. Yu J, Lessaed RB, Bowman LE, Nocera DG. Direct observation of intramolecular energy transfer from a $\beta$-diketonate to terbium (III) ion encapsulated in a cryptand. Chemistry Physics Letters. 1991; 187(3):263-268.

6. Buono-Core GE. Li H. Quenching of excited states by lanthanide ions and chelates in solution. Coordination Chemistry Reviews. 1990; 99:55-87.

7. Molchan IS; Gaponenko NV, Kudrawiec R, Misiewicz J, Bryja L, Thompson GE, Skeldon P. Visible luminescence from europium-doped alumina sol-gel-derived films confined in porous anodic alumina. Journal of Alloys Compounds. 2002; 341(1-2):251-254.

8. Nassar EJ, Ciuffi KJ, Ribeiro SJL, Messaddeq Y. Europium Incorporated in Silica Matrix Obtained by Sol-Gel: Luminescent Materials. Materials Research. 2003; 6(4):557-562.

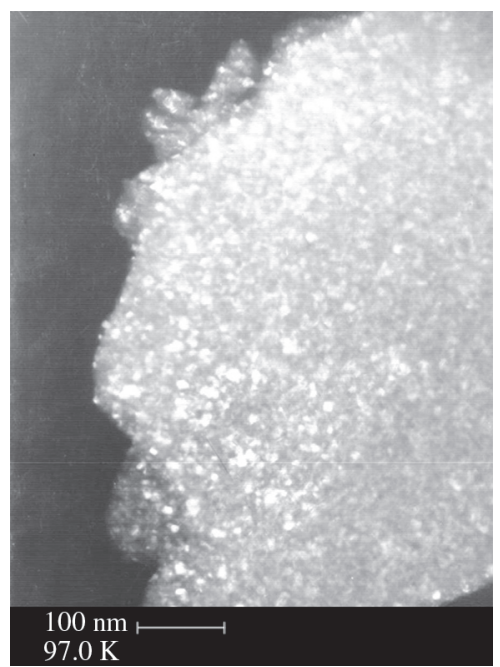

(a)

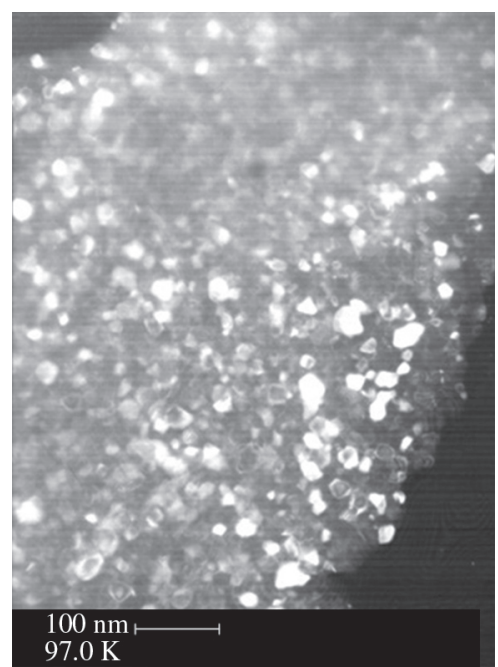

(b)

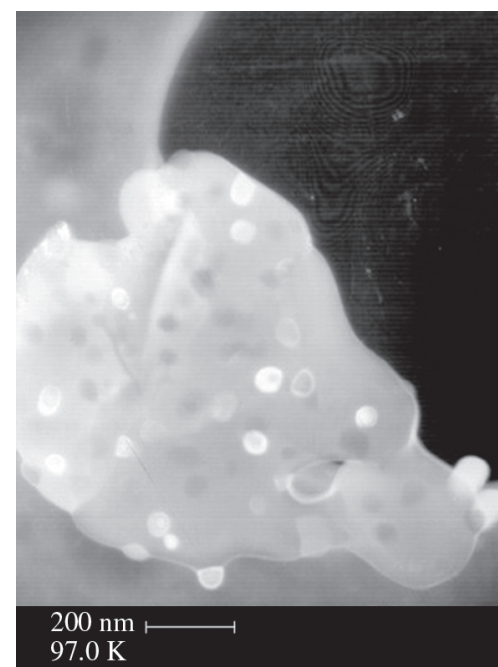

(c)

Figure 4. Transmission Electron Microscopy of the samples heat-treated at, a) $500{ }^{\circ} \mathrm{C}$; b) $750{ }^{\circ} \mathrm{C}$; c) $1000{ }^{\circ} \mathrm{C}$. 
9. Nassar EJ, Serra OA, Calefi PS, Manso CMCP, Neri CR. $\beta$-Diketonates of $\mathrm{Eu}^{3+}$, Red Phosphors, Supported on Sol-Gel Functionalized Silica. Materials Research. 2001; 4(1):18-22.

10. Ciuffi KJ, de Lima OJ, Sacco HC, Nassar E. Eu ${ }^{3+}$ Entrapped in Alumina Matrix Obtained by Hydrolytic and Non-Hydrolytic Sol-Gel Routes. Journal of Non-Crystalline Solids. 2002; 304(1-3):126-133.

11. Zhang HJ, Fu L, Wang SB, Meng QG, Yang KY, Ni JZ. Luminescence characteristics of europium and terbium complexes with 1,10-phenanthroline in-situ synthesized in a silica matrix by a two-step sol-gel process. Materials Letters. 1999; 38(4):260-264.

12. Nassar EJ, Serra OA. Solid state reaction between europium III chloride and Y-zeolites. Materials Chemistry and Physics. 2002; 74(1):19-22.

13. de Sa GF, de Azevedo WM, Gomes ASL. Syntesis and Photophysical and Luminesces. Journal of Chemical Research. 1994; 4:234-235.

14. Sager WF, Filipescu N, Serafin FA. Substituent Effects on Intramolecular Energy Transfer. I. Absorption and Phosphorescence Spectra of Rare
Earth $\beta$-Diketone Chelates. Journal of Physics and Chemistry. 1965; 69(4):1092-1100.

15. Jorgensen CK, Reisfeld R. Judd-Ofelt parameters and chemical bonding. Journal of the Less Common Metals. 1983; 93(1):107-112.

16. Reisfeld R. Spectra and Energy Transfer of Rare Earths in Inorganic Glasses. Structure Bonding. 1973; 13:53-98.

17. Hazenkamp MF, Van der Been AMH, Feiken N, Blasse G. Hydrated rareearth-metal ion-exchanged zeolite a: characterization by luminescence spectroscopy. Part 2.-The Eu ${ }^{3+}$ ion. Journal of the Chemical Society, Faraday Transactions. 1992; 88(1):141-144.

18. Negishi N, Takeuchi K. Structural changes of transparent $\mathrm{TiO}_{2}$ thin films with heat treatment. Materials Letters. 1999; 38(2):150-153.

19. Ukrainczyk L, Bellman RA, Anderson AB. Template Synthesis and Characterization of Layered Al- and Mg-Silsesquioxanes. Journal of Physics and Chemistry B. 1997: 101(4):531-539. 